\title{
СТРАТЕГИЧЕСКИЙ ПОДХОД К ИССЛЕДОВАНИЮ ПАРЕМИЙ В РЕЧИ ПОЛИТИКОВ
}

\section{STRATEGIC APPROACH FOR ANALYZING PAREMIAS IN POLITICIANS' SPEECH \\ O. Semenova}

Summary: The article proves the choice of strategic approach in analyzing paremias in the politicians' speech. The existing in linguistics approach is added with means of lingo-argumentative analysis. The author suggests methodology and conceptual apparatus for analyzing the political discourse. The position of strategic approach is positioned both in private sphere of ling-argumentology and in the whole system of linguistic knowledge.

Keywords: speech, political communication, argumentation, intention, strategic approach, impact.
Семенова Ольга Фиофановна

старший преподаватель, Байкальский государственный

университет

SemOlg1971@rambler.ru

Аннотация: В статье обосновывается выбор стратегического подхода в исследовании паремий в речи политиков. Существующий в лингвистике стратегический подход дополняется средствами лингвоаргументологического анализа. Предлагается методология и концептуальный аппарат стратегического подхода к анализу политического дискурса. Представляется место стратегического подхода не только в частной области лингвоаргументологии, но и в системе лингвистического знания.

Ключевые слова: речь, политическая коммуникация, аргументация, интенция, стратегический подход, воздействие.
Д ля лингвистических исследований конца XX начала XXI века характерна переориентация научных интересов с внутренней стороны логичеязыковой системы в аргументации. Это предполагает широкий спектр изучения языковых явлений, связанных с функционированием языка, что ведет к необходимости задействовать концептуально-методологический аппарат лингвистических подходов и целых парадигм.

В своем исследовании, посвященному функционированию паремий в речи политиков и определению их стратегического потенциала, мы рассматриваем политический дискурс как речь политиков в процессе политической коммуникации. Одной из интенций политика выступает аргументирующая стратегия, при реализации которой достигается цель воздействовать на оценку ситуации и формирование желаемого мнения.

Цель данной статьи заключается в следующем:

- обосновать выбор стратегического подхода в исследовании;

- представить его место не только в частной области лингвоаргументологии, но и в системе лингвистического знания;

- дополнить существующий в лингвистике стратегический подход средствами лингвоаргументологического анализа;

- предложить методологию и концептуальный аппарат стратегического подхода к анализу политического дискурса.
Указанное в начале смещение фокуса исследований объясняет и разные смыслы в определении и последующем использовании базовых категорий исследуемого феномена. Так, под аргументацией может подразумеваться набор утверждений, одно из которых, называемое заключением (в терминологии разных авторов - тезис, утверждение, точка зрения и т.д.), подтверждается на основе других (аргумент, довод, обоснование) при условии логической связи (демонстрации, правила вывода). Аргументация может быть определена как акт убеждения, призванный заставить собеседника поверить, что что-то имеет место.

Важным вопросом стало и понимание диалогического взаимодействия с точки зрения целей интеракции [6]. Проанализировав литературу по исследованию разных типов дискурса, можно заключить, что политический дискурс обладает разной степенью адресатности и персуазивности [3, 14, 2]. Весь спектр возможных целей можно представить в виде шкалы. Крайними точками этой шкалы, используя терминологию исследования Васильяновой, являются понятия «совещательность» и «состязательность». В промежуточном пространстве этой шкалы можно расположить разные типы целей, связанных с действием аргументирования: «рациональное тестирование точек зрения» $[7,207]$, «стремление разделить универсум» [12, с.45] «стремление к истине», «стремление к общему пониманию».

Забегая вперед, отметим, что исследования политического дискурса показывают, что таковой демонстрирует властные интенции, социальную ангажированность, 
стремление преобладать над лагерем противников [5, с.23], то есть по целям тяготеет к экстремуму «состязательность».

Исследования того или иного дискурса, в данном случае политического в лингвоаргументативном ключе, выводит к научному осмыслению ряд аспектов (логикокоммуникативном, когнитивном, социальном, прагматическом), которые невозможно охватить в одном исследовании. Поэтому мы считаем необходимым вести речь о систематике, где аргументация предстает как система. Обоснование и концептуальное содержание системности в исследовании лингвистических объектов разработано в рамках научной школы Г.М. Костюшкиной - инициатора широкого обсуждения проблематики аргументации как системы так или иначе связанной с когнитивной сущностью языка в связи с речемыслительной деятельностью человека и вне зависимости от подхода ученых к этому явлению [11, с. 13]. В цитируемой монографии представлены работы аргументологов в проекции на концептуально-категориальный аспект языка и его систем.

Сказанное обусловливает наш выбор системного подхода, однако считаем возможным уточнить, что под системным подходом мы понимаем не узкий подход, а вектор или принцип системного мышления, который позволяет рассматривать «оперировать понятием системы в отношении сложных и сверхсложных объектов и ставить задачи и <..> моделировать изучаемый объект» [12, с. 193];

Следуя такой научной стратегии следующим шагом является определение некоторой исходной теоретической ориентации в изучении исследуемого нами явления с учетом заявленных в работе объекта и предмета исследования.

Исследование паремий в аргументации само по себе не ново $[1 ; 18]$. Мы считаем, что данные языковые средства представляют собой «индивидуальные и мгновенные проявления речевой деятельности человека говорящего», которые «являются ярким образцом неравновесных структур, где факторы Времени (и Пространства), Хаоса и Уникальности, сочетаясь, рождают свой особенный порядок, который является свойством не каждого отдельного речевого произведения, но всей совокупности речевой практики в рамках определенного национально-лингвокультурного сообщества» [10, c. 7]. Поэтому паремии как клишированные средства языка могут быть рассмотрены в связи с принципами, конституирующими хаос речевой практики, в качестве «дискурсивых значимостей аттрактивности» [9, с. 96] Н.Н. Казыдуб указывает на два вида аттракторов: глубинные смыслы, обосновывающие взаимное притяжение контактирующих личностей и языковые репрезентанты, актуализирующие притягательные смыслы в процессе развертывания дискурса [Там же, с. 94].

Цитаты приведены для того, чтобы показать, что паремии в аргументирующем политическом дискурсе, предполагает исследование в перспективе второго члена методологической оппозиции, о которой мы говорили в начале параграфа. Взаимодействие эмоциональных и когнитивных структур, познавательных установок в ходе осуществления речевых действий представляет коммуникативную сторону аргументации. Термин «аргументативная коммуникация», используемый в контексте политической коммуникации, означает не только логичность в ходе представления некоторого сообщения, но и манифестацию целей, ценностей, мотивов говорящего, а также дополнительные характеристики евентуального, культурного характера. Методологическая оппозиция теперь выглядит таким образом: «рациональная /логическая аргументация - естественно языковая аргументация».

Здесь мы видим возможность задействовать стратегический подход в анализе речевого взаимодействия в рамках коммуникативного подхода в лингвистике. Основы и предпосылки стратегического подхода имеют давнюю традицию изучения и изложены в большом количестве публикаций. [4; 16]. Так называемое стратегическое направление анализа дискурса связано с анализом стратегического планирования речевого взаимодействия. Любая речевая коммуникация - это стратегический процесс, в основе которого лежит выбор оптимальных языковых средств. Единицами анализа в таких исследованиях являются коммуникативная стратегия, коммуникативная тактика, коммуникативный ход. Разнообразие типологии таких единиц объясняется параметрами, положенными в основу типологий. Так, выделяют основные и вспомогательные стратегии [8, с. 56], нарративные и репрезентативные стратегии [19, с. 15], стратегии кооперации и конфронтации [20, с. 78]. Перечень стратегий и тактик носит незаконченный характер, исследователи продолжают выявлять все новые стратегии.

Важным шагом в нашей работе является нахождение такого критерия для выявления стратегий в политическом аргументирующем дискурсе. Считаем вполне обоснованным задействовать такой критерий, обратившись к представленной ранее методологической оппозиции «рациональная /логическая аргументация - естественно-языковая аргументация». Очевидно, что критерием для выявления стратегий в такой перспективе выступает логичность/рациональность коммуникативного акта. Логическая природа последнего в изолированном от контекста «чистом» виде позволит выявить его коммуникативный аналог и далее классифицировать полученные результаты. Языковые ресурсы, и, в частности паремии, как раз и являются теми языковыми репрезентантами, 
которые актуализируют глубинные смыслы, которые в свою очередь могут быть поняты и исследованы с точки зрения коммуникативной цели.

Следует также отметить, что представленные рассуждения логично вписываются в концепцию стратегического маневрирования, которая разрабатывается зарубежными аргументологами [7, с. 24]. Исследования в рамках концепции основываются на идее о том, что в аргументации прослеживаются две категории - рациональность и эффективность, и что в реальных ситуация аргументатор всегда стремится к эффективности.

Не углубляясь в теорию аргументации, остановимся на двух принципиальных для нашей работы положениях. Во-первых, подавляющее большинство политических текстов внутренне строится по типу рассуждения. Во-вторых, мы трактуем термин «аргументация» в широком смысле и вслед за Л.М. Майдановой разводим такие понятия, как аргументация и доказательство. Аргументация имеет целью добиться, чтобы мнение автора стало мнением адресата, она использует естественный язык и обращена к человеку "целостному", к его уму, чувствам и воле» $[15$, с.45]. Поэтому при описании тактик, применяемых в политических текстах, мы говорим прежде всего о форме высказывания, выбранной для манифестации и трансляции суждения и его обоснования, учитывая при этом пресуппозиции массового адресата (мнения, представления, материально-прагматические факторы, этические нормы, вероисповедание и др.).

Воздействие собеседника проявляется не напрямую, а посредством определенных коммуникативных стратегий. Непосредственно языковая реализация персуазивности в политической коммуникации реализует тактики через конкретные языковые средства - пословицы, поговорки, афоризмы и т.д.

В публичной речи приемы фигуры речи особенно важны для достижения экспрессивности и динамичности высказывания. Их главной целью является подчеркивание значимости сказанного, привлечение внимание слушателей.

(1) Хочешь мира, готовься к войне (http://eadaily.com/ ru/news Дата обращения 15.10.2019)

Так российский президент В. Путин ответил пословицей на вопрос о возможной войне во время прямой линии. В приведенном примере пословица является одним из аргументов в поддержку имплицитно выраженного утверждения - тезиса, основная идея которого заключается в том, что Россия - военно-оснащенное государство, позиционирующее себя сильным противником.

С одной стороны, логическая аргументация пред- ставлена актом убеждения, имеющим четкую адресность и персуазивность. Посыл быть наготове направлен на адресата, под которым может подразумеваться любой активно/пассивно участвующий в процессе интеракции. Настоятельная рекомендация - быть во всеоружии выражена эксплицитно, является тактикой призыва к действию, реализуя тем самым персуазивную стратегию.

С другой стороны, убеждение представлено набором утверждений, выраженных как эксплицитно, так и имплицитно, где пословица - аргумент, стилистически оформленная как противопоставление мир-война, используется в поддержку имплицитно выраженного посыла. Армия любого государства должна быть готовой в любой момент защищать страну и народ, демонстрируя свою техническую оснащенность, обороноспособность и подготовленность.

При описании каждой тактики мы попытались вскрыть ее сущность, то есть тот основной коммуникативный ход, который отличает одну тактическую схему от другой даже в группе сходных тактик. На каком же основании вычленяется этот ход? В настоящее время достаточно популярной является дифференциация тактик по интенциональному основанию [8; 17]. Именно на этом основании выделяются дискредитирующие тактики обвинения, оскорбления, издевки. Однако в реальном общении соответствующие интенции реализуются по-разному.

Bсе перечисленные тактики можно объединить одной тактикой анализ-«минус», предполагающей создание негативного образа.

(2) Дай бог вашему теляти нашего волка съесть (https://www.youtube.com/watch?v=ra8xjvFRH1s Дата обращения 15.03.2020)

Пословица была использована президентом В. Путиным для комментирования вопроса о судьбе Крыма. Данная фраза - ироническая реакция российского президента на грандиозные планы, озвученные украинским президентом.

В основание тактического хода могут быть положены принципы организации того или иного жанра или принципы организации текстового фрагмента в рамках определенного типа речи (описания, повествования, рассуждения). Коммуникативный потенциал для организации высказывания есть и у отдельных носителей жанра. Так, широко распространенные маскировочные тактики опираются на такую категорию жанра, как субъектная организация текста. Очень часто основным коммуникативным ходом является «зацепка» за прецедентное высказывание, оттолкнувшись от которого автор реализует дискредитирующую интенцию. В роли такой «зацепки» 
могут выступать как неудачный контекст (высказывание дискредитируемого лица), так и нейтральный контекст, который обыгрывается в негативно-оценочном ключе.

(3) На воре и шапка горит (https://www.fontanka. ru/2016/06/16/145/ Дата обращения 01.12.2019)

Пример реализации дискредитирующей стратегии в речи Министра иностранных дел РФ С. Лаврова осуществляется с помощью использования в речи пословицы. Так российский политик комментирует заявление президента Турции о том, что Россия закупает нелегальную нефть у террористов. Используя пословицу, российский политик имплицитно обличает турецкую сторону в действиях, приписываемых России.

Итак, для обоснования применения стратегического подхода в исследовании паремий в речи политиков сформулируем ряд положений.

Во-первых, в ходе научного исследования предполагается анализ политической коммуникации с элементами аргументации, которая является и методом убеждения, и одной из набора стратегий говорящего. Любая коммуникация, в том числе и аргументативная, всегда стратегична, а стратегии, основанные на критериях рациональности, в политическом дискурсе недостаточно исследованы, отсутствует и типология таковых.
Во-вторых, место стратегического подхода в системном исследовании аргументации находится в области коммуникативной лингвистики. Логика научного поиска при этом объясняется еще и тем, что известна глобальная цель политических интеракций в дискурсе. Это цель влияния и убеждения (состязательность). В проекции на плоскость лингвоаргументологических изысканий наш анализ занимает ту часть исследований, где рассматривается уровень презентации речи в естественноязыковой аргументации. Здесь актуально выявление лингвистических маркеров в виде паремий. В отличие от прагматически немаркированных пропозиций вне реального контекста, функциональное назначение которых можно идентифицировать лишь в аспекте логических рассуждений, пословицы имеют определенную прагматическую установку. Они, как правило, являются заведомо специализированными в своем функциональном статусе, имея значение советов, поощрений, утешений и т.д.

В-третьих, считаем целесообразным использование концепции стратегического маневрирования в связи с возможностью адаптации некоторых идей к стратегическому подходу в лингвистике. Речь идет о понятии идеальной цели, которая имеет риторический аналог. Такая концепция может стать инструментом для анализа коммуникативных стратегий в различных типах дискурса.

\section{ЛИТЕРАТУРА}

1. Аверина С.Н. Пословично-поговорочные паремии как аргументативные средства языка : диссертация ... кандидата филологических наук : 10.02.19. Краснодар, 2005. - 159 c.

2. Васильянова И.М. Особенности аргументации в судебном дискурсе: дисс. ... к. филол. н. Калуга, 2007. 206 с.

3. Вольвак Н.П. Фактор адресата в публичном аргументирующем дискурсе: Автореф.дис...канд.филол.наук:Спец.10.02.01-русский язык / Н.П. Вольвак. Владивосток, 2002. - 26 c.

4. Дейк Т.А. Стратегии понимания связного текста // Новое в зарубежной лингвистике. Вып. 23. - М., 1988. - С. 153-211.

5. Демьянков В.3. Политический дискурс как предмет политологической филологии Текст. / В.3. Демьянков // Политическая наука. Политический дискурс: История-и современные исследования. №3. - М.: Нион РАН, 2002. -С.32-43.

6. Егорова, М.А. Коммуникативные стратегии и тактики слушающего направленные на корректировку неуспешного диалогического дискурса / М.А. Егорова // Закономерности и тенденции развития науки в современном мире. -Уфа : 000 «Агентство международных исследований», 2015. - С. 44-46.

7. Eemeren \& Grootendorst, A Systematic Theory of Argumentation. The Pragma-Dialectical Approach. Cambridge University Press, Cambridge, 2004

8. Иссерс 0.С. Коммуникативные стратегии и тактики русской речи. Изд. 5-е. - М.: Издательство ЛКМ, 2008. - 288 с.

9. Казыду6 Н.Н. Дискурсивные значимости аттрактивности. https://cyberleninka.ru/article/n/diskursivnye-znachimosti-attraktivnosti

10. Колмогорова А. Аргументация в речевой повседневности. Изд-во «Флинта», 2009. - 152 с.

11. Костюшкина, Г.М. Аргументация и концептуальная систематика речи и речевой деятельности / Г.М. Костюшкина, Н.С. Баберина // Концептуальная систематика аргументации. - М.: ФЛИНТА, Наука, 2016. - С. 10-70

12. Костюшкина Г.М. В поисках системообразующего механизма в языке. Вестник ИГЛУ, Иркутск, 2012. С. 128-133

13. Косяков В.А. Реферативный обзор книги Д. МакКуэйла «Теория массовой коммуникации» (1 часть) / В.А. Косяков, Е.А. Универсалюк // Вопросы теории и практики журналистики. - 2019. - Т. 8, № 3. - С. 524-534.

14. Ощепкова Н.А. Стратегии и тактики в аргументативном дискурсе: прагмалингвистический анализ убедительности рассуждения (на материале политических дебатов). Автореф... канд. филол. наук. - Тверь, 2004. - 18 с.

15. Майданова Л.М. Аргумент к человеку в публицистической аргументации https://cyberleninka.ru/article/n/argument-k-cheloveku-v-publitsisticheskoyargumentatsii

16. Макаров М.Л. Основы теории дискурса Текст. / М.Л. Макаров. М.: ИТДГК «Гнозис», 2003. - 280с. 
17. Миронова П.О. Стратегия редукционизма в современном политическом дискурсе: когнитивно-прагматический аспект. Автореф. ... канд. филол. наук. Екатеринбург, 2003. -23 с.

18. Серегина М.А. Паремии в дискурсе речевого воздействия. https://cyberleninka.ru/article/n/paremii-v-diskurse-rechevogo-vozdeystviya

19. Седов К.Ф. 0 жанровой природе дискурсивного мышления языковой личности Текст. / К.Ф. Седов // Жанры речи-2. Саратов, 1999. - С. 13-26.

20. Третьякова В.С. Конфликт в лингвистических категориях. https://cyberleninka.ru/article/n/konflikt-v-lingvisticheskih-kategoriyah-1

\section{( С Семенова Ольга Фиофановна (SemOlg1971@rambler.ru).}

Журнал «Современная наука: актуальные проблемы теории и практики»

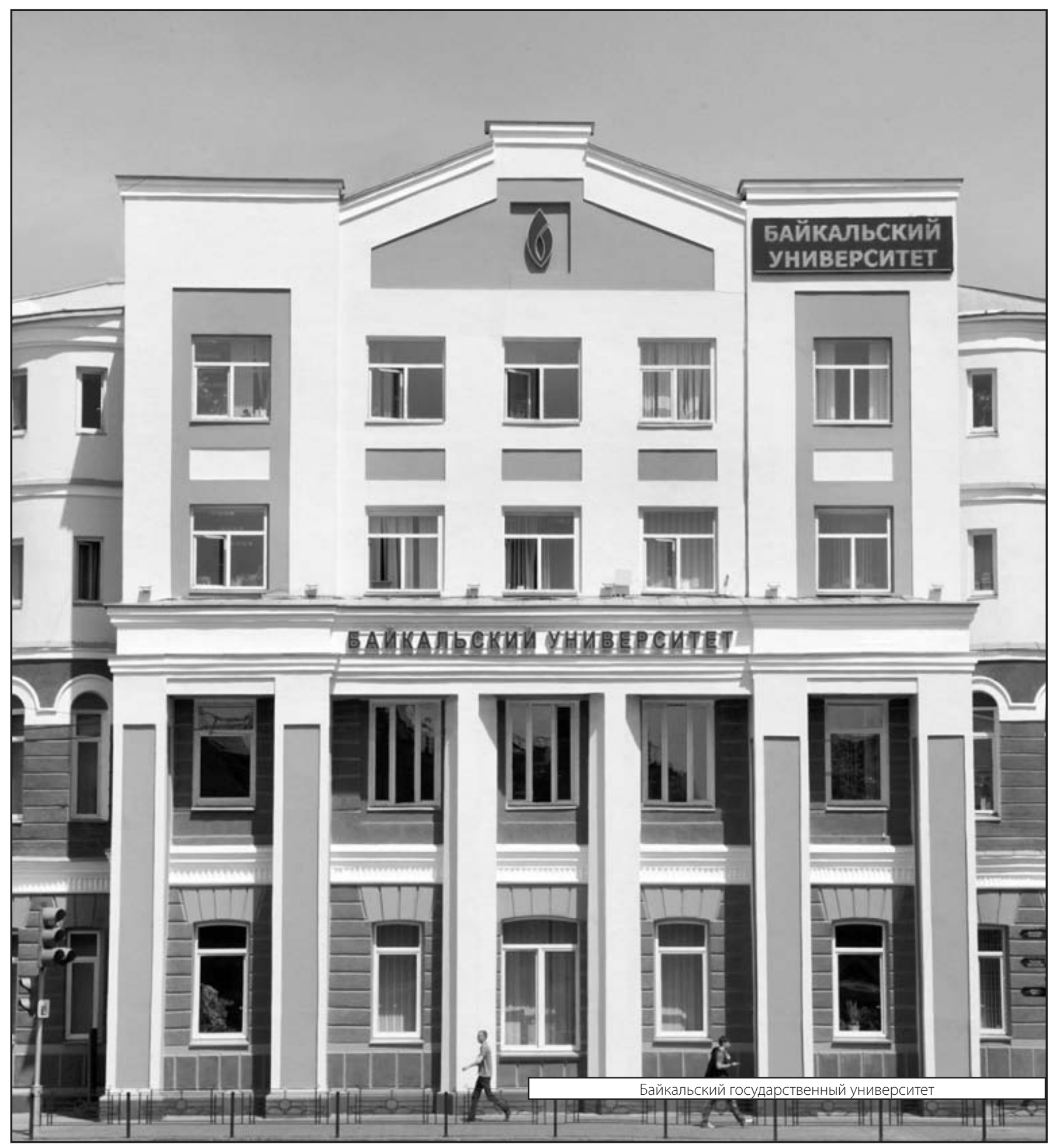

